\title{
Haematological Parameters in open angle Glaucoma Patients
}

\author{
${ }^{1}$ G. A. Akinlabi and ${ }^{2}$ V. I. Iyawe
}

\begin{abstract}
There is potential for blood related factors to affect aqueous production or optic nerve functions. There have been relationships between inflammatory cell count and glaucoma. Eosinophils have inverse relationship with steroids which is used to induce ocular hypertension. Here we compare hematological parameters for a group of 68 chronic openangle glaucoma (OAG) patients and a non-glaucomatous group of 71. In our hematological analysis we determined the concentration of the various white blood cells (WBC), and packed cell volume (PCV). In the blood cell analysis, we found a significantly lower eosinophil in the glaucoma group (2.54\% to $4.03 \%)$. There were no significant differences for the PCV, $(40.47 \%$ to $41.97 \%$ ), white blood cell total/mm3 (5105.97 to 4802.98 ) Lymphocyte, (50\% to $50.73 \%$ ), Neutrophil, (44.8\% to $42.5 \%$ ), Monocyte, (1.76\% to 1.97\%), Basophil (0.35\% to0.53\%). Of the hematological characteristics considered, in the blood analysis we found only the eosinophil count to have a significant relationship to glaucoma.
\end{abstract}

\section{INTRODUCTION}

Glaucoma is the second leading cause of blindness in Nigeria, (incidence 19\%) ${ }^{1}$. Unlike cataract $(23 \%)$, which is the leading cause of blindness it has no known cure. In particular it is the leading cause of blindness amongst African Americans and Hispanics in the US. Age, race, a positive family history, corneal thickness and an elevated intraocular pressure (IOP) have consistently been

KEYWORDS: OAG, IOP, Eosinophils, Prostaglandin, Steroids.

${ }^{1}$ Department of Optometry and ${ }^{2}$ Department of Physiology, University of Benin, Benin City.

All correspondence and/or request for reprints should be directed to: G.A. AKINLABI, Department of Optometry University of Benin, Benin City. shown to be major risk factors in open angle glaucoma (OAG).

The increase in intra ocular pressure (which presently is the yardstick for monitoring the disease) in turn depends on either increase in production of aqueous humour and or blockage of aqueous humor drainage. The aqueous humor is a circulatory fluid through which the lens and cornea receive their nutrients and is derived from the blood in the ciliary body and iris through the ciliary epithelium ${ }^{2}$. Hence, the connection between glaucoma and blood.

Primary hematological diseases are uncommon, while haematological manifestations secondary to other diseases occur frequently. Hemorrhagic glaucoma is a complication of vascular pathology. 
During the last decade, the presumed etiology of glaucoma has moved from a pure pressure concept to a combined mechanical and vascular theory ${ }^{3}$. Hyperviscosity due to alterations of blood cells and plasma components can induce microvascular damage ${ }^{4}$. Impaired availability of nitric oxide, endothelia dysfunction and vasospasm are being increasingly linked with glaucoma. ${ }^{3,4}$ Armani investigated the link between steroids, eosinopenia and glaucoma. ${ }^{5}$

Blood examination is performed for almost all patients with major illness because of the importance of determining the presence of anemia or leukocyte changes. Other abnormalities may be detected in the blood, by either quantitative or qualitative studies, by measuring Packed cell volume, total white cell and differential white cell count.

Our objective is to investigate if glaucoma has any relationship with any of the haematological parameters, having in mind the close relationship between aqueous humour and blood on the one hand and the rich vascular supply to the optic nerve head where most of the glaucoma damage takes place on the other.

\section{METHODOLOGY}

The sample population was from the glaucoma clinic of the University of Benin
Teaching Hospital Benin City Nigeria, Nigerian Army Eye Clinic Bonny Camp Lagos Nigeria, and the Lagos Island General Hospital, Lagos Nigeria. After informed consent of the authority and the subjects, about $5 \mathrm{ml}$ of blood was collected from the ante cubital fossa vein of each of the 68 glaucoma subjects, using a clean disposable $5 \mathrm{ml}$ plastic syringe into an EDTA bottle. Some of the controls were patients visiting the eye clinic for one ocular problem or the other apart from glaucoma while majority were mainly year two medical students of University of Benin. This accounted for the significant age difference between the patient and the control.

All the studied glaucoma patients were taking medication and the most popular medications were timolol, pilocarpine and diamox.

PCV was then measured for each sample using micro hematocrit method ${ }^{6}$. Total leukocyte count, by the use of Leichmans stain and microscope ${ }^{7}$. Lishman's stain was used for differential WBC count with microscope following the manual method $^{7}$.

The results were analysed using the statistical package for social sciences (SPSS). The frequency, range, mean standard deviation, standard error and unpaired t-test for each parameter were determined. 


\section{RESULTS}

Table1 shows the mean values, standard deviations (SD) and standard errors (SE) for all the haematological parameters, (PCV, WBC total and differential) for patients and controls. A column for normals from another study is included ${ }^{8}$.

TABLE 1:

\begin{tabular}{|r|c|c|c|c|}
\hline & $\begin{array}{c}\text { Norms (from } \\
\text { Ezeilo 1977) }\end{array}$ & $\begin{array}{c}\text { Glaucomas } \\
\mathbf{( n = 6 8 )}\end{array}$ & $\begin{array}{c}\text { Controls } \\
\text { (n= 71) }\end{array}$ & Significance (p) \\
\hline Packed Cell Vol \% & 50 & $40.5(3.6)$ & $42.0(6.8)$ & 0.123 \\
Lymphocytes \% & 45 & $51.42(1826)$ & $4803(1436)$ & 0.197 \\
Monocytes \% & 5 & $50.7(10.1)$ & $50.7(11.6)$ & 0.836 \\
Neutrophil \% & 40 & $45.0(11.1)$ & $42.5(11.7)$ & 0.198 \\
Basophils \% & 1 & $0.35(0.77)$ & $0.53(0.89)$ & 0.232 \\
Eosinophils \% & 10 & $2.5(2.4)$ & $4.0(2.4)$ & 0.004 \\
\hline Age & & $53.6(16.6)$ & $29.8(15.9)$ & 0.000 \\
\hline
\end{tabular}

Table 1: Values (mean, standard deviation and level of significance) from the analysis of blood components of 68 glaucoma patients, and 71 non-glaucomatous subjects.

The mean PCV in patients was $40.48 \%$ $\pm 3.62 \%$ and that of control was $41.97 \% \pm$ $6.77 \%$. The mean count for WBC total, was $5105.97 \pm 1825.65 / \mathrm{mm} 3$ for patient and $4802.97 \pm 1436.22 / \mathrm{mm} 3$ for control. In WBC differential count, the mean results were lymphocytes $50.69 \pm 10.14 \%$ for patients and $50.74 \pm 11.56$ for controls, neutrophils $44.81 \pm 11.10 \%$ for patients and $42.54 \pm 11.68 \%$ for controls, moncoytes $1.77 \pm 2.05 \%$ for patients and $1.97 \pm 1.81 \%$ for controls, eosinophils $2.55 \pm 2.44 \%$ for patients and 4.03 \pm 3.41 for controls and lastly basophils $0.34 \pm 0.76$ for patients and $0.53 \pm 0.89$ for controls.

The table also showed that there was no significant difference between the means of the patients and controls in all the parameters measured except for age and eosinophil count. The mean of patient's age was $53.57 y$ yrs and that of control was 29.76yrs; t-test showed that there was a very significant difference between these means and the level of significance was 0.0001. The mean eosinophil count in patients was $2.55 \%$ and $4.03 \%$ in controls; t-test shows 0.0052 tailed significant difference.

\section{DISCUSSION}

The subjects in this study were not agematched. However, most of the parameters studied are no longer affected by age after adulthood. It has also been documented that inflammatory cell counts change little with advancing age in primary glaucoma patient ${ }^{9}$. 
The high point in the result of this study was that there is no significant difference in the comparison of the means of PCV, WBC, total and differential between AOG patients and control except in eosinophil count. The mean eosinophil count in patients is $2.55 \%$ and in controls $4.03 \%$, $(p<0.005)$. There are several possible explanations for the reduced eosinophil count (eosinopenia), in patients.

It has been shown that both eosinophil count and IOP respond to circadian rhythm or diurnal variation. Eosinophil count is highest at (mid) night during sleep, lowest in the morning and rises by mid afternoon ${ }^{10}$. In reverse order IOP has been reported to be lowest at about midnight, highest in the morning and decreases by mid afternoon ${ }^{11}$.

ACTH affects both eosinophil count and IOP but in opposite direction.

Steroids reduce eosinophil counts. It has been shown that dexamethasone exerted a direct survival-inhibitory effect on eosinophil ${ }^{12}$, while it induces elevated $\mathrm{IOP}^{13}$. Earlier Armaly ${ }^{5}$ failed to demonstrate heterogeneity in the eosinopenic and ocular hypertensive response, but he didn't rule out a significant relationship between the two.

Stress causes reduction in eosinophil count $^{14}$, while elevation of IOP was associated with anxiety, anger and depression and a lower IOP occurs when the patient was relatively happy and relaxed.

As in circadian rhythm there is also inverse effect of exercise on eosinophil count and IOP. Excessive exercise reduces eosinophil count and raises IOP, while moderate exercise raises eosinophil count and reduces IOP.

Epinephrine causes eosinopenia15. It has also been reported to cause maculopathy. Whereas administration of the -adrenergic blocking agent propranolol prevents the eosinopenia of epinephrine administration, it may induce a rise of $30 \%$ in the blood eosinophil count. 16,17 -adrenergic blocking agent e.g Timolol is one of the main drug of treatment in lowering IOP.
Human eosinophils possess the Prostaglandin D2 (PGD2) adenylyl cyclasecoupled receptor; this is expected to inhibit their activation. In contrast, it was found that prostaglandin D2 is a potent stimulator of eosinophil chemotaxis, actin polymerization, CD11b expression, and L-selectin shedding. These responses are specific for eosinophils, as neutrophils display little or no response to prostaglandin D218. There is also a link between vascular endothelia and release of PGI2 whose dysfunction will lead to vasospasm-glaucoma3. These show that prostaglandin enhances activation of eosinophil and prostaglandin analog latanoprost is the current drug of use in lowering IOP.

A look at the extra cellular matrix of the glaucomatous lamina cribosa shows that marked changes have been reported in the extra cellular matrix of the cribriform plates of the glaucomatous lamina cribosa, there is an increase in the amount and density of collagen type VI, especially in the core of the plates. Collagen type VI is normally located at the edge of the cribriform plates and as particle of staining in the core. The rearrangement has been suggested to be either due to loss of neural tissue owing to elevated intra ocular pressure or as a result of weakness in the connective tissue that permits the glaucomatous excavation of the optic nerve head to progress in response to elevated IOP. These lamina cribosa cells are broad, flat and markedly sensitive to growth factor PDGF, suggesting that they are a form of neuroglial cells. Eosinophils have also been reported to have $\mathrm{Ca} 2+$ dependent collagenase, that is able to, degrade type I and III collagen19,20, hence the redistribution of collagen on the optic nerve is probably due to eosinophil too.

According to the DANGER model suggested by21, immune system is more concerned with damage than with foreignness, and is called into action by alarm 
signals from injured tissues such as those exposed to pathogens, toxins, mechanical damage, and so forth. Some of these endogenous, non foreign alarm signals are mammalian DNA, RNA, heat shock proteins (Hsps), interferon- (an inducible protein often made by virus-infected cells), interleukin-1, CD40-L. This model defines as dangerous anything that induces stress or nonphysiological death of a cell. Thus the increase in IOP, which causes mechanical damage, can also set off immunological reactions according to this theory.

\section{CONCLUSION}

Therefore we are suggesting that the role of eosinophilic cells or what happens to eosinophils in glaucoma should be thoroughly investigated; probably eosinopenia may be a strong risk factor in glaucoma. Considering the role of blood in the formation of aqueous and the nourishment of the retina, immunological aspect of glaucoma is worth a second glance.

\section{References}

1) Kragha IK: Causes of blindness in northern Nigeria. Am J Optom Physiol Opt. 1987 Sep;64(9):708-10.

2) Davson H, and Hollingsworth JR: The effects of iodate on the blood-vitreous barrier.ExpEye Res. 1972 Jul;14(1):21-8.

3) Delaney Y, Walshe TE and O'Brien C (2006) Vasospasm in Glaucoma: Clinical and Laboratory Aspects. Optometry and Vision Science, Vol 83, no 7, July 2006406414.

4) Mannini L, Cecchi E, Fatini C, Marcucci R, Alessandriello A, Matucci-Cerinic M, Abbate R, Gensini GF: Clinical hemorheology and microcirculation. Ann 1st Super Sanita 2007 43(2): 144-155.
5) Armaly MF: Dexamethasone ocular hypertension and eosinopenia, and glucose tolerance test. Arch Ophthalmol. 1967 Aug;78(2):193-7.

6) Wintrobe MM, Lee GR, Boggs DR, Bitheel TC, Athens JW and Foerster J. (1974) Clinical Haematology. Lea \& Febiger philadephia (7th) pp 9-23.

7) Hall R and Malia RG: (1986). Medical Laboratory $\mathrm{Ha}$ ematology. Buutterworths \& co. London. 99-118.

8) Ezeilo GC: Physiological peculiarities of Africans: (1977) In Green JH An Introduction to human physiology: African Edition Ibadan: Oxford University press (iv) 225-232.

9) Gwyn-DR; Stewart-WC; Hennis-HL; McMillan-TA; Pitts-RA; (1993) The influence of age upon inflammatory cell count and structure in chronic open-angle glaucoma: (1993) Acta Ophthalmology-Copenh. 1993 Oct: 71(5):691-5.

10) Dahl R, Venge P, Olsson I: Blood eosinophil leucocytes and eosinophil cationic protein. Diurnal variation in normal subjects and patients with bronchial asthma. Scand J Respir Dis. 1978;59(6):323-5.

11) Larsson, Lill-Inger: Intraocular pressure over 24 hours after singledose administration of latanoprost $0.005 \%$ in healthy volunteers. A randomized, double-masked, placebo controlled, cross-over single center study. Acta Ophthalmologica Scandinavica 79 (6), 567-571.

12) Lamas AM, Leon OG, Schleimer RP: Glucocorticoids inhibit eosinophil 
responses to granulocyte-macrophage colony-stimulating factor. J Immunol. 1991 Jul 1;147(1):254-9.

13) Bartlett JD, Woolley TW, Adams CM: Identification of high interlobular pressure responders to topical ophthalmic corticosteroids. J Ocul Pharmacol. 1993 Spring;9(1):35-45.

14) Hardy WR \& Anderson RE, Hypereosinophilia. Ann Intern Med. 1968 Dec;69(6):1331-2.

15) Anderson V, Bro-Rasmussen F, Hougaard K: Autoradiographic studies of eosinophil kinetics: effect of cortisol: Cell Tissue Kinet 2:139, 1969.

16) Koch-Weser J: Beta adrenergic blockade and circulating eosinophils. A r c h Intern M ed. 1968 Mar;121(3):255-8.
17) Zucker-Franklin D; Eosinophil function and disorders Adv Intern Med 19:1, 1974.

18) Monneret G, Li H, Vasilescu J, Rokach J and Powell WS (2002) 15-Deoxy12,14-prostaglandins D2 and J2 are potent activators of human eosinophils. J Immunol 168: 35633569.

19) Hibbs MS, Mainardi CL, Kang AH. Type-specific collagen degradation by eosinophils. Biochem J. 1982 Dec 1;207(3):621-4.

20) Davis WB, Fells GA, Sun $\mathrm{X}-\mathrm{H}$, et al: Eosinophil mediated injury to lung parenchyma cells and interstitial matrix J clin invest 74:269.1984.

21) Matzinger P: An innate sense of danger. Does the immune system really discriminate between self and non-self. Science 2002 296(5566) 301-5. 